\title{
Scaling up access to oral rehydration solution for diarrhea: Learning from historical experience in low- and high-performing countries
}

Shelby E. Wilson ${ }^{1}$, Saul S. Morris ${ }^{1}$, Sarah Skye Gilbert ${ }^{1}$, Emily Mosites², Rob Hackleman², Kristoffer L.M. Weum², Jillian Pintye ${ }^{2}$, Lisa E. Manhart², Stephen E. Hawes ${ }^{2}$

\section{${ }^{1}$ Bill \& Melinda Gates Foundation, Seattle, USA \\ ${ }^{2}$ University of Washington Strategic Analysis Research and Training (START) Program, Seattle, USA}

\begin{abstract}
Aim This paper aims to identify factors that systematically predict why some countries that have tried to scale up oral rehydration solution (ORS) have succeeded, and others have not.

Methods We examined ORS coverage over time, across countries, and through case studies. We conducted expert interviews and literature and data searches to better understand the history of ORS scale-up efforts and why they failed or succeeded in nine countries. We used qualitative, pairwise (or three-country) comparisons of geographically or otherwise similar countries that had different outcomes in terms of ORS scale-up. An algorithm was developed which scored country performance across key supply, demand and financing activities to quantitatively assess the scale-up efforts in each country.
\end{abstract}

Results The vast majority of countries have neither particularly low nor encouragingly high ORS use rates. We observed three clearly identifiable contrasts between countries that achieved and sustained high ORS coverage and those that did not. Key partners across sectors have critical roles to play to effectively address supply- and demand-side barriers. Efforts must synchronize demand generation, private provider outreach and public sector work. Many donor funds are either suspended or redirected in the event of political instability, exacerbating the health challenges faced by countries in these contexts. We found little information on the cost of scale-up efforts.

Conclusions We identified a number of characteristics of successful ORS scale-up programs, including involvement of a broad range of key players, addressing supply and demand generation together, and working with both public and private sectors. Dedicated efforts are needed to launch and sustain success, including monitoring and evaluation plans to track program costs and impacts. These case studies were designed to inform programmatic decision-making; thus, rigorous academic methods to qualitatively and quantitatively evaluate country ORS scale-up programs might yield additional, critical insights and confirm our conclusions.

\section{Shelby E. Wilson}

Correspondence to:

Associate Program Officer (Child Health)

Integrated Delivery

Bill \& Melinda Gates Foundation

P.O. Box 23350

Seattle, WA 98102

Shelby.Wilson@gatesfoundation.org
Oral rehydration therapy (ORT) for dehydrating diarrhea came into routine use at Bangladesh's Cholera Research Laboratory (now ICDDR,B) in 1969. Nine years later, the World Health Organization recommended a 
standardized version of the therapy - Oral Rehydration Salts, or ORS - for all acute watery diarrhea in children [1]. However, on average between 2006 and 2011, only one third of children with diarrhea in developing countries received ORS [2].

These low rates of ORS use are surprising given the emphasis given to this product in the years after its introduction. The product was one of the foci of UNICEF's "GOBIFFF" selective primary health care strategy of 1982 (the "O" in GOBI refers to ORS) [3]. In the mid-1990s, ORS was similarly made the keystone of diarrheal disease management in WHO's "Integrated Management of Childhood Illness" initiative [4], and The Lancet child survival series of 2003 identified it as the single intervention available at that time with the greatest potential to save lives [5]. Yet throughout this period, ORS gained ground at a rate of just 0.6 percentage points per year (analysis based on data available online from UNICEF [6], MEASURE DHS [7] and other national surveys).

Twenty countries (out of a total of 96 with data from the standard surveys series that track ORS coverage, including Demographic and Health Surveys (DHS) [6] and Multiple Indicator Cluster Surveys (MICS) [8]) have entirely failed in promoting rational diarrhea management, with less than $25 \%$ of pediatric diarrhea episodes treated with ORS. Yet many other countries have done much better, with 29 countries using ORS in one half or more of all episodes, and eight countries using ORS in two-thirds or more of all episodes. As can be seen in the map (Figure 1), by this criterion, high performing countries are found in every region of the world. The vast majority of countries in sub-Saharan Africa, as well as many Indian states, have neither particularly low nor encouragingly high rates of ORS use, but rather fall somewhere in the middle.

The objective of the present study was to address the question: Why have some countries succeeded in scaling up ORS for diarrhea, when others tried and failed? We hypothesized that countries would be more likely to have been successful in scaling up ORS if they simultaneously: 1) made significant improvements to the standard product offering, including lowering the price; 2) conducted widereaching marketing campaigns; 3 ) acted to remove regula- tory barriers to the sale and promotion of ORS in the private sector; 4) improved private provider knowledge of rational diarrhea management; 5) improved public provider knowledge of rational diarrhea management; 6) made a concerted effort to improve the regularity of supply; and 7) mobilized partner funding as well as taking country ownership of the program. Some of these concepts have been examined in previous case studies [1,9] but we are not aware of any other work that has examined all of them simultaneously. To test these hypotheses we reviewed peerreviewed articles and grey literature and conducted key informant interviews to learn about the history of ORS scale-up in each of the selected countries, completed qualitative case studies using information obtained from literature searches and interviews, and quantitatively analyzed the findings from these sources.

\section{METHODS}

We categorized every country with ORS coverage data into three categories: countries that exceeded $50 \%$ coverage for $\geq 5$ years and now have achieved $>66 \%$ coverage were defined as "sustained success" (Table 1); countries that achieved $>50 \%$ coverage at one point in time, then saw reductions in coverage of at least ten percentage points were defined as "unsustained success" (Table 2); and countries never reaching ORS coverage rates of $25 \%$ despite targeted scale-up efforts were defined as "non-starter (failure)" (Table 3).

We did not expect coverage of ORS in any country to exceed $75 \%$ because the average duration of an episode of pediatric diarrhea is 3.1 days, and approximately $25 \%$ of all episodes are of such brief duration (or mild presentation) that they do not significantly contribute to mortality and morbidity [10] . Caregivers are therefore not motivated to seek treatment outside the home. Although ORS is recommended for all episodes [2], we view a use rate of $75 \%$ as the maximum level that can be achieved at a population level.

Nine countries were purposively selected for in-depth case studies, including Bangladesh [11], Guyana [12], India [13], Madagascar [14], Malawi [15], Senegal [16], Sierra Leone [17], Tanzania [18], and Trinidad and Tobago [19]. These included all of the possible sustained successes ex-

Table 1. Countries meeting the criteria for "sustained" success

\begin{tabular}{lcccc} 
Country & $\begin{array}{c}\text { First year ORS } \\
\text { coverage }>50 \%\end{array}$ & $\begin{array}{c}\text { Most recent year } \\
\text { ORS coverage }>50 \%\end{array}$ & $\begin{array}{c}\text { Most recent coverage } \\
\text { measured level }\end{array}$ & $\begin{array}{c}\text { Total number of years } \\
\text { coverage }>50 \%\end{array}$ \\
\hline Democratic People's Republic of Korea & 1994 & 2011 & 77.6 & 17 \\
\hline Malawi & 2000 & 2009 & 74.0 & 9 \\
\hline Sierra Leone & 2001 & 2010 & 69.1 & 9 \\
\hline Thailand & 2003 & 2010 & 72.6 & 7 \\
\hline
\end{tabular}

ORS - oral rehydration solution 

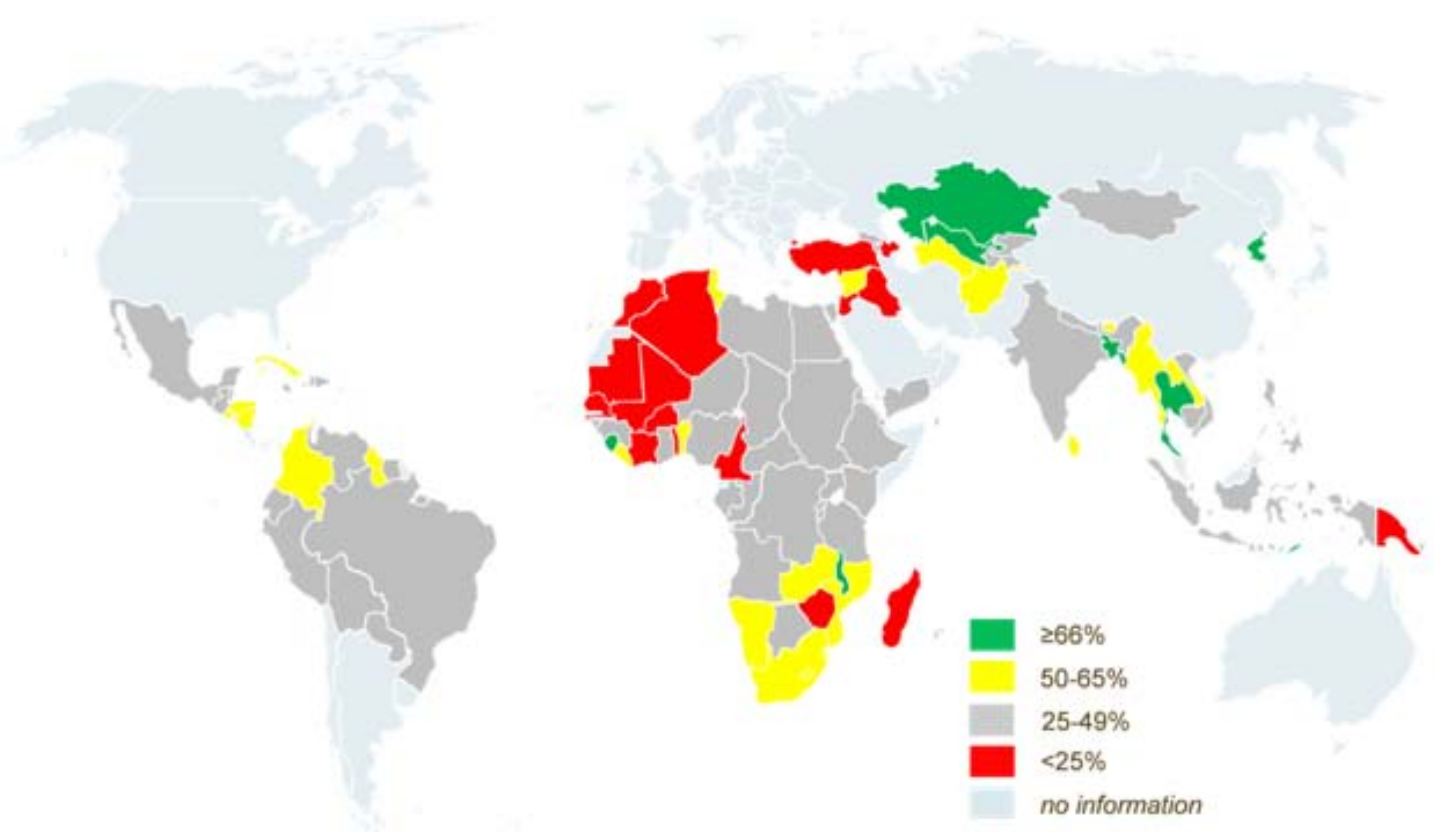

Figure 1. Map of ORS use rates around the world. (Data sources: Demographic and Health Surveys, Multiple Indicator Cluster Surveys and national survey series).

Table 2. Countries meeting the criteria for "unsustained success"

\begin{tabular}{lcccc} 
Country & $\begin{array}{c}\text { Maximum ORS } \\
\text { coverage reached }\end{array}$ & $\begin{array}{c}\text { Year maximum } \\
\text { coverage reached }\end{array}$ & $\begin{array}{l}\text { Subsequent decline in } \\
\text { coverage }\end{array}$ & $\begin{array}{c}\text { Most recent year ORS } \\
\text { coverage reported * }\end{array}$ \\
Kazakhstan & 73.3 & 2006 & 11.5 & 2011 \\
\hline Lesotho & 54.5 & 2000 & 12.1 & 2004 \\
\hline Mongolia & 55.9 & 2000 & 17.9 & 2005 \\
\hline Swaziland & 85.7 & 2007 & 20.1 & 2010 \\
\hline Trinidad and Tobago & 52.3 & 1987 & 13.9 & 2010 \\
\hline United Republic of Tanzania & 57.6 & 1992 & & 2000 \\
\hline
\end{tabular}

ORS - oral rehydration solution

*At time of classification for this study.

Table 3. Countries meeting the criteria for "non-starters"

\begin{tabular}{lcc} 
Country & $\begin{array}{c}\text { Maximum ORS } \\
\text { coverage reached }\end{array}$ & $\begin{array}{c}\text { Number of data } \\
\text { points }\end{array}$ \\
\hline Burkina Faso & 21.2 & 5 \\
\hline Cameroon & 21.9 & 5 \\
\hline Chad & 23.4 & 4 \\
\hline Côte d'Ivoire & 22.7 & 5 \\
\hline Madagascar & 23.1 & 4 \\
\hline Mali & 15.7 & 3 \\
\hline Mauritania & 23.3 & 2 \\
\hline Morocco & 24.4 & 3 \\
\hline Senegal & 22.4 & 5 \\
\hline Togo & 20.2 & 5 \\
\hline Turkey & 15.9 & 2 \\
\hline Zimbabwe & 20.9 & 3
\end{tabular}

ORS - oral rehydration solution cept for the Democratic Republic of Korea, where we knew that we would not be able find relevant information, and Thailand, which was excluded arbitrarily. We matched these successes to one "non-starter" country which was geographically close by and plausibly comparable in terms of size and health system organization. India was included as a historic comparator for Bangladesh because it was a "non-starter" until 2005, even though coverage has improved since that time; because of its subsequent change in status, when we scored this country for the quantitative analysis we only considered events up to 2005. Tanzania was studied as an interesting case of an "unsustained success" which could reasonably be compared to both Malawi (a "sustained success" scale-up country) and to Madagascar (a "non-starter"). In order to include a pair of case studies from the western hemisphere-where no country has 
reached our standard of "sustained success"-we included Guyana, where coverage reached $49.8 \%$ in 2009 , and compared it to Trinidad and Tobago, a clear "unsustained success". We conducted similar case studies of zinc uptake in four countries, including Bangladesh [20], Madagascar [21], Nepal [22], and Tanzania [23]. However, because there is more information and longitudinal data, we focused this manuscript on ORS scale-up.

In each country, literature reviews and expert interviews were conducted to better understand the history of ORS scale-up efforts and why they failed or succeeded. The review included peer-reviewed articles, conference presentations, and grant reports available to the Bill \& Melinda Gates Foundation and partners. An initial search was conducted in PubMed in April 2012 and the titles and abstracts of all the retrieved citations were examined for relevance to ORS scale-up efforts in each country. Following the initial search, multiple searches were conducted in PubMed and Google through October 2012 to identify studies and reports related to ORS scale-up in the selected countries. The search strategy was restricted to documents written in English and French. The following keyword terms (in English) were used with each country: ORS, ORT, and diarrhea.

Additional articles and reviews related to the relevant topics were identified by hand-searching the references in the articles and reports identified through the search engines. We also sought additional literature from the United $\mathrm{Na}$ tions Children's Fund [24], the World Health Organization [25], and the World Bank [26] websites. Reports from USAID (United States Agency for International Development)-funded projects were retrieved from the USAID Development Experience Clearinghouse [27].

Data for a wide range of monitoring and impact evaluation indicators in the areas of population, health, and nutrition were obtained from Demographic and Health Surveys [28], Multiple Indicator Cluster Surveys [29], and Malaria Indicator Surveys [30]. Information about the characteristics of health facilities and services available in a country was obtained from Service Provision Assessment Surveys [31]. Data on drug prices, availability and affordability were obtained from the World Health Organization/Health Action International surveys and reports [32].

The "snowball" technique was used to identify informants. An initial list of potential key informants was generated through personal communication with experts in the field of diarrhea management, with the aim of interviewing individuals from a range of sectors to provide a broad range of perspectives. Potential key informants from governments, donors, multilateral and bilateral organizations, non-governmental organizations (NGO), the local private sector, and academic and clinical institutions were contacted individually via email to request telephone or, in some cases, in-person interviews. Between April and September 2012, key informant interviews were conducted with 58 experts (Table 4) to understand what efforts were made improve ORS use in the past, and how, with the benefit of hindsight, well-informed observers think these efforts could have been better designed in each of the nine countries. The interviewers took notes during and after the interviews to document the key informants' responses.

An interview tool (Online Supplementary Document) was developed to guide the discussion and to ensure that the primary questions were answered. Semi-structured interviews were used to elicit open-ended responses. Not all interviewees were asked exactly all the same questions despite utilization of the same interview guide, given the semi-structured nature of the interviews, and that differing perspectives were sought from each type of partner. We circulated the draft case studies to local key informants with requests for their review and comment. The case studies were finalized following this validation.

The team used qualitative, pairwise (or three-country) comparisons of geographically or otherwise similar countries that had different outcomes in terms of ORS scale-up. In addition to the qualitative pairwise (or three-country) comparisons of country case studies, the scale-up efforts in each country were quantitatively assessed, based on a numeric scoring of country performance across various key supply, demand and financing activities. For each case study, we scored the country on their efforts along seven dimensions of implementation, with a range of scores from 0 (low/no effort) to 2 (high effort). The sum of these scores yields an implementation score ranging from 0 to 14 . The seven dimensions of implementation included the following: made significant improvements to the standard product offering, including lowering price; conducted widereaching marketing campaigns; acted to remove regulatory barriers to sale and promotion of ORS in the private sector; improved private provider knowledge of rational diarrhea management; improved public provider knowledge of rational diarrhea management; made a concerted effort to improve the regularity of supply; mobilized partner funding as well as taking country ownership of the program.

The quantitative portion of evaluation was conducted through a scoring algorithm. Scoring was made as consistent as possible across countries by developing precise definitions of what was included in "0", "1" or "2" scores for each dimension (Table 5). Since not all countries had the same data availability, scoring definitions generally had 2-3 components so that countries with non-equivalent information could still be classified. After scoring each component, aggregate scores were calculated for each country by summing across components. A statistical test was conducted with the aim of rejecting the hypothesis that there 
Table 4. Dimensions of implementation and their scales

\begin{tabular}{|c|c|c|}
\hline Dimension & Definition & Scale \\
\hline Political stability & $\begin{array}{l}\text { The degree to which a country has had } \\
\text { minimal political conflict, civil unrest and/or } \\
\text { violence }\end{array}$ & High-Medium-Low \\
\hline Natural disasters & $\begin{array}{l}\text { The number of natural disasters experienced } \\
\text { by the country during the ORS or zinc } \\
\text { scale-up time period }\end{array}$ & High-Medium-Low \\
\hline U5 mortality & U5 No. deaths & U5 No. deaths \\
\hline U5 deaths due to diarrhea & U5 No. deaths due to diarrhea & U5 No. deaths due to diarrhea \\
\hline Vaccine coverage & The immunization rate & \% DTP3 \\
\hline Zinc introduction & Whether the country has introduced zinc & Y/N \\
\hline Private sector share & $\begin{array}{l}\text { Of those seeking care for diarrhea, \% going } \\
\text { to private sector }\end{array}$ & $\%$ going to private sector \\
\hline USAID recipient & $\begin{array}{l}\text { Whether the country has received funding } \\
\text { from USAID }\end{array}$ & $\mathrm{Y} / \mathrm{N}$ \\
\hline $\begin{array}{l}\text { Home-based solutions } \\
\text { promotion }\end{array}$ & $\begin{array}{l}\text { Whether the country initially promoted } \\
\text { home-based sugar-salt solutions }\end{array}$ & $\mathrm{Y} / \mathrm{N}$ \\
\hline IMCI country & Whether the country has introduced IMCI & Y/N \\
\hline $\begin{array}{l}\text { Decentralization of } \\
\text { responsibility not funding }\end{array}$ & $\begin{array}{l}\text { Whether the country has decentralized } \\
\text { responsibility without also decentralizing } \\
\text { funding }\end{array}$ & 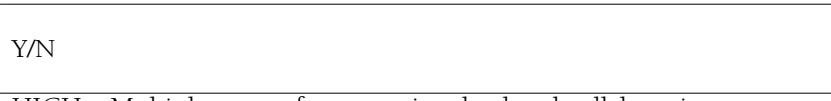 \\
\hline $\begin{array}{l}\text { Degree of collaboration } \\
\text { across government, private, } \\
\text { public }\end{array}$ & $\begin{array}{l}\text { Extent to which partners worked together } \\
\text { on diarrhea case management }\end{array}$ & $\begin{array}{l}\text { HIGH - Multiple types of partners involved and collaborating } \\
\text { MEDIUM - Multiple types of partners involved but tense relations OR } \\
\text { few partners but strong relations } \\
\text { LOW - No partnerships, or a few non-collaborative ones }\end{array}$ \\
\hline Female literacy rate & Self-explanatory & $\%$ females literate \\
\hline Diarrhea care-seeking & $\begin{array}{l}\text { Degree to which caregivers sought treatment } \\
\text { for diarrhea when their child fell ill }\end{array}$ & $\%$ seeking care \\
\hline Reach of health system & Quality of the health infrastructure & $\begin{array}{l}\text { HIGH - Infrastructure has broad reach and HCW capacity appropriate } \\
\text { for pop size } \\
\text { MEDIUM - Broad reach OR appropriate HCW capacity } \\
\text { LOW - Insufficient reach and poor capacity }\end{array}$ \\
\hline Surface area & Self-explanatory & square $\mathrm{km}$ \\
\hline Population & Self-explanatory & No. people \\
\hline \multicolumn{3}{|l|}{ SCALE-UP INDICATORS } \\
\hline $\begin{array}{l}\text { Improved product, } \\
\text { including pricing }\end{array}$ & $\begin{array}{l}\text { Degree to which scale-up attempt improved } \\
\text { the ORS or zinc product, including making } \\
\text { it affordable }\end{array}$ & $\begin{array}{l}\text { HIGH - Price not a barrier to purchase; consumer research conducted } \\
\text { to determine preferences } \\
\text { MEDIUM - Generally strong product, but price or consumer research } \\
\text { sub-optimally conducted } \\
\text { LOW - Pricing and product not informed by any prior information }\end{array}$ \\
\hline Marketing campaign & $\begin{array}{l}\text { Degree to which scale-up attempt } \\
\text { conducted a successful direct-to-consumer } \\
\text { marketing campaign }\end{array}$ & $\begin{array}{l}\text { HIGH - Multi-channel, researched campaign of sufficient duration; } \\
\text { consumer demand increased } \\
\text { MEDIUM - Multi-channel or of long duration; high knowledge low } \\
\text { utilization } \\
\text { LOW - Little impact on awareness and/or use after the campaign }\end{array}$ \\
\hline Regulatory approval & Whether regulatory hurdles were overcome & $\mathrm{Y} / \mathrm{N}$ \\
\hline $\begin{array}{l}\text { Improved private provider } \\
\text { knowledge }\end{array}$ & $\begin{array}{l}\text { Degree to which campaign successfully got } \\
\text { private providers to recommend ORS and/or } \\
\text { zinc }\end{array}$ & $\begin{array}{l}\text { HIGH - For areas where high use of private providers, specific } \\
\text { interventions targeting private providers; for others, inclusion in } \\
\text { outreach; positive impact on provider recommendations } \\
\text { MEDIUM - Inclusion in outreach, awareness but not impact } \\
\text { LOW - Not included in outreach }\end{array}$ \\
\hline $\begin{array}{l}\text { Improved public provider } \\
\text { knowledge; increasing } \\
\text { supportive supervision }\end{array}$ & $\begin{array}{l}\text { Degree to which campaign successfully got } \\
\text { public providers to recommend ORS and/or } \\
\text { zinc }\end{array}$ & $\begin{array}{l}\text { HIGH - For areas where high use of public providers, specific interven- } \\
\text { tions targeting private providers; for others, inclusion in outreach; } \\
\text { positive impact on provider recommendations } \\
\text { MEDIUM - Inclusion in outreach, awareness but not impact } \\
\text { LOW - Not included in outreach }\end{array}$ \\
\hline $\begin{array}{l}\text { Increasing availability of } \\
\text { supply }\end{array}$ & $\begin{array}{l}\text { Degree to which scale-up including local } \\
\text { manufacturing, and consistent availability of } \\
\text { quality product }\end{array}$ & $\begin{array}{l}\text { HIGH - Few stockouts, local supplier, private and public } \\
\text { MEDIUM - Modest number of stockouts, foreign supply, private or } \\
\text { public } \\
\text { LOW - Low availability }\end{array}$ \\
\hline Financing of scale-up & $\begin{array}{l}\text { Degree to which countries successfully } \\
\text { began to own scale-up and both scale-up } \\
\text { and maintenance had sufficient funds }\end{array}$ & $\begin{array}{l}\text { HIGH - Partners contribute but country assume ownership; sufficient } \\
\text { funding in volume and duration } \\
\text { MEDIUM - Partners contribute or country ownership, but funding } \\
\text { insufficient } \\
\text { LOW - Few contributors; insufficient funding }\end{array}$ \\
\hline
\end{tabular}

ORS - oral rehydration solution, U5 - under 5 years of age, DTP3 - Diphtheria-tetanus-pertussis, USAID - United States Agency for International Development, IMCI - Integrated Management of Childhood Illness, No.- number, Y/N - yes/no

was a trend in the aggregate scores across the three categories of countries ( $\mathrm{H} 1$ : score $_{\text {sustained_success }}>$ score $_{\text {unsustained_ }}$ success $>$ score $_{\text {non-starter }}$ ). The test used was Cuzick's non-parametric trend, which is an extension of the Wilcoxon rank-sum test [33]. Given that the scoring criteria demanded a certain degree of subjectivity in order to classify countries with different types of data, we urge caution in interpreting these results. 
Table 5. Number and type of key informants accessed for each country

\begin{tabular}{|c|c|c|c|c|c|c|c|c|}
\hline Country & Government & Donor & $\begin{array}{l}\text { Multilateral } \\
\text { and bilateral }\end{array}$ & $\mathrm{NGO}$ & $\begin{array}{l}\text { Local private } \\
\text { sector }\end{array}$ & Academia & Clinical & Total \\
\hline Bangladesh & 0 & 1 & 0 & 2 & 2 & 1 & 0 & 6 \\
\hline Guyana & 1 & 0 & 1 & 0 & 0 & 0 & 1 & 3 \\
\hline India & 0 & 0 & 0 & 3 & 1 & 0 & 0 & 4 \\
\hline Madagascar & 1 & 0 & 0 & 7 & 0 & 0 & 0 & 8 \\
\hline Malawi & 1 & 0 & 1 & 4 & 0 & 0 & 0 & 6 \\
\hline Senegal & 0 & 1 & 1 & 1 & 0 & 0 & 1 & 4 \\
\hline Sierra Leone & 1 & 1 & 0 & 5 & 0 & 0 & 0 & 7 \\
\hline Tanzania & 1 & 0 & 2 & 7 & 1 & 0 & 0 & 11 \\
\hline Trinidad and Tobago & 0 & 0 & 3 & 1 & 0 & 0 & 2 & 6 \\
\hline Multi-country input & 0 & 0 & 0 & 3 & 0 & 0 & 0 & 3 \\
\hline Total & 5 & 3 & 8 & 33 & 4 & 1 & 4 & 58 \\
\hline
\end{tabular}

NGO - Non-governmental organization

Table 6. Scores given to each country for each scale-up criterion

\begin{tabular}{|c|c|c|c|c|c|c|c|c|c|}
\hline Scale-up indicators & Bangladesh & Malawi & $\begin{array}{l}\text { Sierra } \\
\text { Leone }\end{array}$ & Guyana & Tanzania & $\begin{array}{l}\text { Trinidad } \\
\& \text { } \\
\text { Tobago }\end{array}$ & Senegal & India* & Madagascar \\
\hline $\begin{array}{l}\text { Improved product, including } \\
\text { pricing }\end{array}$ & 2 & 2 & 1 & 1 & 0 & 1 & 1 & 1 & 1 \\
\hline Marketing campaign & 2 & 2 & 2 & 2 & 0 & 1 & 0 & 1 & 0 \\
\hline Regulatory not a barrier & 2 & 2 & 2 & 2 & 2 & 2 & 2 & 2 & 2 \\
\hline $\begin{array}{l}\text { Improved private provider } \\
\text { knowledge }\end{array}$ & 1 & 2 & 0 & 1 & 1 & 2 & 0 & 0 & 1 \\
\hline $\begin{array}{l}\text { Improved public provider } \\
\text { knowledge; increasing } \\
\text { supportive supervision }\end{array}$ & 2 & 1 & 2 & 2 & 0 & 2 & 1 & 1 & 1 \\
\hline Increasing availability of supply & 2 & 2 & 2 & 1 & 0 & 1 & 0 & 1 & 1 \\
\hline Financing of scale-up & 2 & 1 & 1 & 2 & 0 & 2 & 0 & 0 & 0 \\
\hline TOTAL & 13 & 12 & 10 & 11 & 3 & 11 & 4 & 6 & 6 \\
\hline
\end{tabular}

*Up to 2005

\section{RESULTS}

\section{Country comparisons}

Country comparisons are presented in Figure 2.

Comparison 1: Sierra Leone vs Senegal. The West African country of Sierra Leone, mired in civil war from 19912002 , is a perhaps unexpected example of sustained, successful scale-up. Even before the civil war, Blue Flag Volunteers (BFVs) were trained to promote hygiene and treat diarrhea with ORT. During the conflict, which displaced as many as 2 million out of the 5.5 million population, ORS was pushed heavily on displaced populations in camps. After the civil war, the primary health care system was "reinvented", with multi-donor support. Recurrent cholera outbreaks were managed with ORS and efforts were made to ensure that the supply chain was maintained at each level: the Ministry of Health and Sanitation increased the intensity of tracking ORS distribution, districts and communities were in charge of ordering supplies, and peer supervisors facilitated re-stocking ORS in Community Based Distributors' (CBDs) kits. The population learned about the product via interpersonal communications with very active community promoters (BFVs and or CBDs). Integrated community case management of childhood illness was introduced to some districts in late 2000s and free health care for pregnant and lactating women and children under-five was introduced in 2010 [34-37].

Senegal is a West African country of 13 million people where ORS scale-up efforts have not succeeded ("nonstarter"). The country is very stable, with a well-organized health system and relatively good infrastructure. The United States provided over half of all bilateral aid for health (basic) in the 2000s. USAID has been promoting ORS in Senegal since 1985, through multiple, successive, standalone "Technical Assistance" programs in "USAID regions" in the West - including PRITECH (1985-1993), BASICS (1994-2006), Child Survival Program (1998-2002), Fatick Partnership (2007-2009), Community Health Program (2006-2011). UNICEF supplied all ORS in the country until 2000 and Integrated Management of Childhood Illness (IMCI) was introduced in the 2000s, but the guidelines resulted in no change in clinical practice. The "health hut" program was launched in the late 1990s, including activities to promote both ORS and home fluids (including sugar-salt solution). However, ORS was not widely avail- 

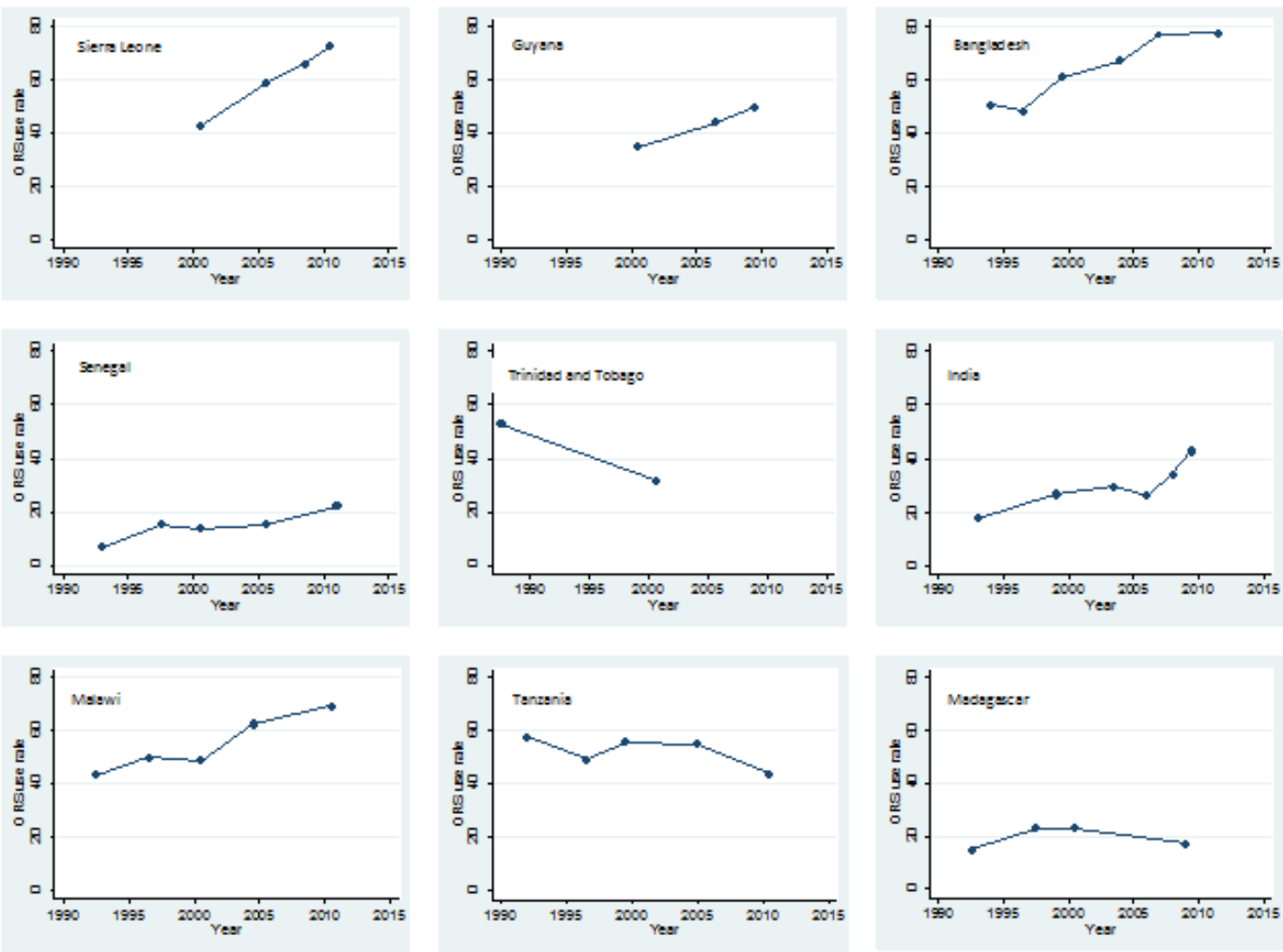

Figure 2. Oral rehydration solution (ORS) use rates by country, 1987-2011.

able in Senegal due to a weak distribution system that caused frequent shortages and stock-outs: availability of essential drugs was highest at the storage facilities and decreased at the more peripheral health facilities [38]. There are now 1600 health huts in Senegal, but they recover the full cost of medicines and, when surveyed, few (6-47\%) health providers knew how to correctly look for signs of dehydration [39].

There are four key lessons from this comparison. First, interpersonal communications led to universal familiarity with ORS in Sierra Leone, whereas $41 \%$ of the population in Senegal still does not know about this product [40]. In Sierra Leone, emergencies provided an opportunity for boosting confidence in the product, and its purpose (rehydration, not symptom relief) is understood and appreciated. This understanding has been undermined in Senegal by mixed messaging about the benefits of ORS vs sugarsalt solution.

Second, basic supply chain management kept ORS widely available in Sierra Leone; in Senegal, it was unavailable in the private sector because ORS does not have a "visa" required to register drug products [36] and therefore could not be sold as a medicine, and public sector availability was also inconsistent. Further, pricing favored ORS in Sierra Leone, where the product is cheaper than in Senegal and where the cost of sugar made home-produced alternatives unaffordable (also not the case in Senegal). Finally, the re- gional stand-alone project approach of USAID in Senegal appears to have been too limited in scope and scale to increase ORS usage, compared to the "national reconstruction project" in Sierra Leone, launched with lots of donor support to restore infrastructure and health services, and through which a comprehensive community case management program was created. Key informants suggested that there was limited government spending on scale-up efforts in Senegal during the period under consideration.

Comparison 2: Guyana vs Trinidad and Tobago. Guyana is a "sustained success" country of just 742 thousand people, in South America but culturally of the Caribbean. The country is susceptible to flooding and experienced a cholera epidemic in 1992 [41]. After the 1992 cholera epidemic, Guyana created a national policy for the treatment of diarrhea, including ORS. The Ministry of Health purchased large quantities of ORS, including pre-mixed liquid, and stockpiled product for disasters. The country's dense network of public health centers and health posts was supplemented by 287 Community Health Workers who extended the reach into deep rural areas and demonstrated correct use of ORS. According to key informants, the Ministry of Health conducted yearly, seasonal marketing for ORS, using newsprint, television, and radio and made ORS available free in the public sector.

Trinidad and Tobago is an "unsustained success" Caribbean country of 1.2 million people and is relatively wealthy 
with abundant oil and gas. Key informants recalled that a single local champion established Oral Rehydration Units in three major hospitals/health centers in the capital in 1981, in conjunction with an early 1980s ORS marketing campaign funded by the International Development Research Center (IDRC, US\$ 132 thousand), which used a logo on printed materials and also ran radio and television spots. One radio station hosted a call-in program with health care providers and focused on diarrhea prevention. Key informants suggested that the campaign was intended to be both relevant to and empowering for mothers, and relied on mother-to-mother interpersonal communication to disseminate messages. Messaging switched to promoting "rehydration", and there was even distracting debate over merits of coconut water as a source of liquidand electrolytes [42]. Ultimately, scale-up of water and sanitation improvements has been associated with a major reduction in diarrhea incidence; diarrhea is no longer seen as national priority since diarrheal disease accounted for less than $1 \%$ of deaths among children under-five in 2010 [43].

This comparison illustrates that ORS is very hard to promote if it is not epidemiologically relevant. Although both countries experienced declines in mortality to low levels, ORS retained relevance in Guyana because of repeated outbreaks of diarrheal disease after flooding. This comparison underscores the essential nature of broad national buy-in. The program in Trinidad and Tobago relied on one person and external funding, whereas Guyana has embraced ORS as part of its commitment to universal primary health care, with the government even taking on responsibility for regular communication campaigns. Finally, clarity of message is essential. In Trinidad and Tobago, the messaging was inconsistent between ORS, breastfeeding, and even coconut water, whereas Guyana made a strong and lasting commitment to ORS, and folded this seamlessly into integrated programs such as Integrated Management of Childhood Illness (IMCI).

Comparison 3: Malawi, Tanzania and Madagascar. Malawi is a land-locked country in Eastern/Southern Africa with 16.3 million people and successfully sustained scaleup. The country has never had significant civil unrest or natural disasters. Malawi implemented a National Control of Diarrheal Disease Program in 1985 and stopped promoting sugar-salt solution in 1989, using multiple channels to popularize ORS (so that $90 \%$ of the population was familiar with it by 1992). Integrated Management of Childhood Illness (IMCI) was rolled out comprehensively to all districts and a cadre of "Cholera Assistants" was instituted in the 1970s. These were developed into Health Surveillance Assistants now present in all "hard-to-reach" communities of the country [44]. From the early 2000s, USAID funded Population Services International (PSI) to socially market branded ORS, achieving universal recognition, and mas- sive penetration of pharmacies and retail outlets. The product was free in the public sector and heavily subsidized in the private sector [45].

Tanzania has 46.9 million people and was classified as an "unsustained success" for ORS scale up because it achieved greater than 50\% coverage and then declined. Tanzania implemented a National Control of Diarrheal Diseases Program in the 1980s, with "Diarrhea Treatment Corners" in health centers and hospitals and achieved 93\% familiarity with ORS by 1991 [46]. The IMCI Strategy was gradually rolled out and evidence from a local trial showed that IMCI did not improve ORS use [47]. Although ORS was widely available in the public sector in 2006 [48], availability appears to have fallen (to $57.4 \%$ ) by 2009 for unclear reasons [49]. A local producer (Shelys) did little to stimulate demand, relying on public tenders; the second local supplier went bankrupt in 2008. USAID-funded outreach to pharmacists and Accredited Drug Dispensing Outlets (ADDOs) resulted in good availability from the early 2000s, but conducted little marketing beyond these segments [50]. There was little direct-to-consumer marketing of ORS in Tanzania except through USAID's Point-of-Use Water Disinfection and Zinc Treatment (POUZN) project (2005-2010) which was all non-branded promotion and time-limited [51]. Unlike Malawi, Tanzania lacks a community health worker program at scale. ORS is not always free in the public sector and there is no subsidy.

Madagascar is an island of 22.0 million people and was classified as a "non-starter" for ORS scale-up because it never reached greater than $23.1 \%$ coverage. It has experienced a relentless series of natural disasters, and, in 2009, widely perceived to have been unconstitutional transfer of power. There was no ORS in country at all until 1988. UNICEF then supported a local producer with limited capacity, which eventually went out of business, leaving the country wholly dependent on imported supply. While many countries import health products, key informants suggested that the frequency with which Madagascar experienced natural disasters and the political turmoil that led to import disruptions resulted in poor accessibility of ORS. Early radio campaigns promoted both ORS and home-made sugar-salt solution. USAID supported co-packaged products only through the POUZN Project from 2008 to 2010 but diverted support to non-government entities following a transfer of power, which severely weakened program efforts to scale-up ORS [52].This diversion likely contributed to the poor penetration of programs for training public providers and community-based distribution, which reached $<10 \%$ and $15 \%$, respectively, of the country.

This comparison reveals that once universal familiarity with ORS is achieved, availability is extremely important. Malawi achieved very high levels of availability in both public and 
private sectors, whereas in Madagascar, uptake has been crippled by lack of availability. In Tanzania, the weakening public sector supply chain may explain recent declines in ORS use. An organized cadre of trained community-based distributors can greatly extend the reach of the public sector to achieve market penetration at scale. It is possible to capitalize on floods and cholera epidemics to increase familiarity with and trust in ORS, but countries enmeshed in political unrest are not conducive to ORS scale-up. Reliance on a single donor is risky because support may be abruptly terminated before programs are mature.

Comparison 4: Bangladesh vs India. Bangladesh, a South Asian country of 161 million people, was the first country in the world to accumulate large-scale experience using ORT. It is home to the world renowned International Centre for Diarrhoeal Disease Research (ICCDR,B). ICDDR,B developed ORT and continues to research and promote the approach, modeling successful control of diarrhea mortality. In 1981, the government created the National Oral Rehydration Project and distributed packets of ORS to health centers in 100/509 sub-districts [53]. Between 1980 and 1990, BRAC (formerly Bangladesh Rural Advancement Committee) trained 12 million women (approximately half of all women in the country) in preparation and use of sugar-salt solution, and still trains community health workers [51]. Bangladesh explicitly switched from promotion of sugar-salt solution to promotion of ORS. Starting in 1985 Population Services International (PSI) and, later, the Social Marketing Company (SMC) promoted branded ORS through multi-channel social marketing, spending US\$ 1 million/year and capturing $80 \%$ of the market. In the early 2000s, SMC built its own manufacturing facility and services 220000 retail outlets [54]. According to key informants, in addition to SMC, there are now 30-40 ORS suppliers. ORS is supplied for free in the public sector and is very cheap in the private sector (US\$ 0.06) [52]. Bangladesh relied on the family unit to sustain ORS use - the majority of mothers now educate their children on ORS, removing the need for repeated marketing campaigns. The most recent DHS survey provides clear evidence of successful ORS scale-up efforts: $77.6 \%$ of recent diarrhea episodes were treated with ORS (and 40.8\% were treated with zinc), and only $2.0 \%$ of all under-five deaths were attributed to diarrhea [55].

India's 1.2 billion people reside in 28 states and seven Union Territories, each with hugely different public health systems and health outcomes. India was classified as a "nonstarter" through 2005 then had dramatic increases in coverage. India's multiple large scale government programs-including Diarrheal Disease Control Program (1978), Child Survival and Safe Motherhood Program (1992), Reproductive and Child Health Program (1997), and National Rural Health Mission (2005)_have resulted in high ORS availability in the public sector and training and stocking of outreach workers such as Anganwadi Workers and, more recently, Accredited Social Health Activists (ASHAs). In the 1980s, UNICEF promoted sugar-salt solution [56], which is still more familiar and more widely used than ORS. There is no national consensus in favor of ORS. The Program for Advancement of Commercial Technology-Child and Reproductive Health (PACT-CRH), a US\$ 30 million USAID project, began strong promotion of ORS in the mid-2000s, with celebrity partnerships, media, home visits, and free samples [57]. India's vibrant pharmaceutical industry actively markets antibiotics to private providers, who command at least two-thirds of the market [58]. Public health detailing to private providers has never been done at scale.

This comparison underscores that even in countries where the market for diarrhea treatment is dominated by the informal private sector; it is possible to achieve high levels of use of ORS by changing social norms. It is likely that intensive interpersonal communication is a critical part of this behavior change, and it is also important to directly reach frontline providers at scale. Conversely, an excessive emphasis on public sector providers, in a context where, according to key informants, the public sector is undervalued and under-utilized, is not likely to be very effective, at least in the short term. Branded marketing can be very helpful, but must be explicitly directed at the mass market (India's most successful Electral brand has never been marketed as a product intended for self-treatment).Unambiguous messaging that home-made sugar salt solution is not an adequate substitute for ORS is critical for successful scale-up. Bangladesh benefited from the leadership of a highly respected local institutional champion for ORS (ICDDR,B) and managed to create a broad alliance of major local stakeholders. In India, the major champions of ORS have been mostly external, and there is no equivalent of BRAC that reaches beyond the public sector.

\section{Quantification of scale-up factors analysis}

There was strong evidence that the aggregate scale up scores were more favorable in the countries that achieved more sustainable scale-up, ie, countries that exceeded $50 \%$ coverage for $\geq 5$ years and now have achieved $>66 \%$ coverage ( $P=0.042$, Cuzick's non-parametric test for trend; Figure 3$)$. Although the very small sample size suggests caution when interpreting between group differences in individual implementation categories (Table 6), there is overwhelming evidence that the four successful countries all implemented well-researched, multi-channel communications campaigns, whereas this was not done at all in the two "non-starter" countries, and only to a very limited extent in the three "unsustained success" countries. The 


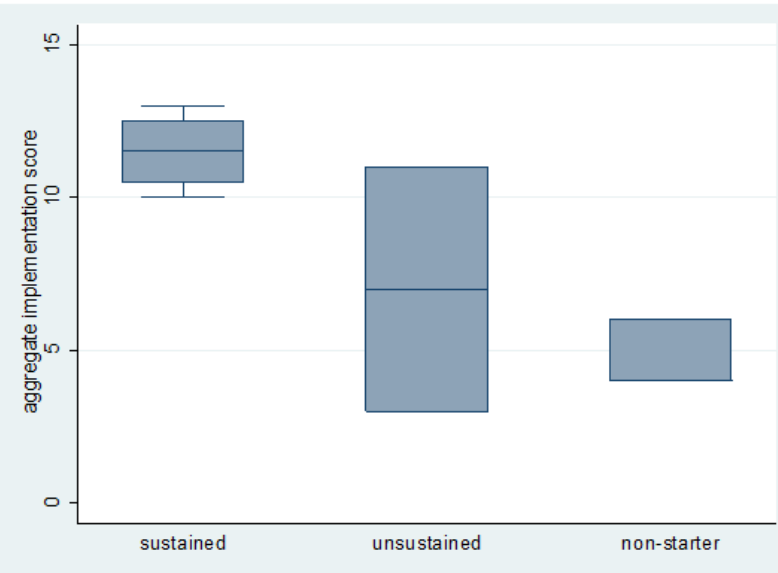

Figure 3. Aggregate implementation scores, by country scale-up type. Box plot with whiskers from minimum to maximum scores for the "sustained success" countries. The whiskers indicate the range of the data and are represented as vertical lines ending in a small horizontal line. The median and the interquartile range (IQR) were used to construct each box. The horizontal bar in the middle is the median score and the height of the box is equal to the IQR, drawn so that it starts at the $25^{\text {th }}$ percentile (lower quartile value) and stops at the $75^{\text {th }}$ percentile (upper quartile value).

next strongest association was with the financing of scaleup, where the more successful countries were more likely to have mobilized substantial funds from partners and taken significant ownership themselves.

\section{DISCUSSION}

Since UNICEF placed ORS at the heart of its "GOBI-FFF" strategy in 1982, usage of ORS has increased slowly but steadily, suggesting a systematic response to public health recommendations [1]. Despite global efforts over the past four decades, however, current ORS use rates in the developing world are surprisingly low. While some countries have not succeeded in promoting rational diarrhea management and others have done much better, most countries are somewhere in the middle. This exercise was designed to explore the root causes of this diversity in ORS use, particularly focusing on direct and indirect contributors to ORS scale-up in countries with very high and very low ORS use rates.

Our initial hypotheses were mainly confirmed - that is, countries were more likely to have been successful in scaling up ORS if they (i) ensured both broad national buy-in and collaboration between government, non-government and private sectors; (ii) made significant efforts to synchronize demand generation, private provider outreach, and public sector work; and (iii) the context at the time of the interventions was conducive to scale up, including funding directed to ORS scale-up and the absence of political turmoil. We also drew some preliminary conclusions about specific elements of scale-up programs, though we believe these will need further validation. While these concepts are not entirely original and novel, we are not aware of any other work that has examined all of them simultaneously.

Key informant interviews suggested that partner collaboration was especially critical to success in Sierra Leone, Bangladesh and Guyana. The governments in all three countries collaborated with a range of development partners in the public and private sectors, reducing potential for "donor dependency". Senegal's reportedly weak government engagement in the early stages of ORS scale-up efforts and reliance on USAID were both cited by key informants as drivers of continuing low ORS use rates. Similar findings were reported from a case study in Philippines as our findings from Trinidad and Tobago: hospital admissions attributable to severe diarrhea declined and ORS became less epidemiologically relevant as income and sanitation improved [1].

The results of the quantification of scale-up factors analysis, despite relying heavily on qualitative information, suggested a correlation between high ORS use rates and synchronicity of demand-and supply-side interventions. All four "sustained successes" (Sierra Leone, Guyana, Malawi, and Bangladesh) focused on community-level delivery (although operationalized in very different ways), promoted ORS through health worker communications and mass media, provided ORS free of charge in public sector and had secure supply of the product. Malawi and Bangladesh have historically had robust community- and household-level interventions that highlight the importance of interpersonal communications to increasing uptake of ORS, and ensuring availability in areas close to where people live. Malawi also utilized tracking mechanisms to reduce stock-outs, and Bangladesh had a sales force for private sector outreach. "Non-starter" countries generally lacked coordinated, sustained efforts to improve supply and demand, and efforts were reportedly hindered by poor country ownership and insufficient financing. For example, the ADDOs in Tanzania can extend the reach of drug shops to rural areas, but given the vast distances in the country, gaps remain for certain segments of the population. Both Madagascar and, more recently, Tanzania struggled to maintain product availability at public health facilities, which may have contributed to low ORS use in those countries.

One of the most surprising findings was the importance of the context in which the scale-up efforts were implemented. The case studies show how clearly it played a role in the outcomes of scale-up efforts, and how there is no "onesize-fits-all" approach or program for ORS. The case study of Madagascar demonstrates how difficult it is to implement successful treatment programs when the health sys- 
tem is passing through a period of acute destabilization. This highlights the importance of fully understanding the risks of working in potential high-impact, volatile countries, where the need is great but the risk of program disruption is very high. However, we should note that many of the countries that we included in the case studies were relatively stable compared to Madagascar, so further studies to support or negate this hypothesis, and to better understand how to successfully operate in high-risk, highneed areas, will be critical moving forward.

We identified four other findings that merit further investigation. First, ambiguous messaging about the relative value of ORS vs home-made sugar-salt solution can stifle ORS utilization. The definition of "oral rehydration therapy" changed four times within a decade [1], and may have had a lasting impact on clarity of communications about the gold standard for treatment of diarrhea. In Tanzania and India, both of which have a vibrant pharmaceutical market, the lack of focus on ORS messaging has allowed this product to be displaced by anti-diarrheals and antibiotics. In contrast, unambiguous messaging, that home-made sugar salt solution is not an adequate substitute for ORS, is critical for successful scale-up. Bangladesh switched from promotion of sugar-salt solution to promotion of ORS and the recent estimates suggest that ORS packets were used in nearly $80 \%$ of under-five diarrhea episodes in 2011. Second, rigorous commercial marketing approaches should be combined with effective interpersonal communication. An earlier case study of ORT success in Egypt highlighted the importance of utilizing scientific evidence with consumer and market research in crafting relevant and appropriate messages [8]. Commercial partners who truly understand marketing, and favor branded over generic marketing, can team up with groups providing interpersonal communication delivered in the home or through self-help groups. Third, it is clear that the market for diarrhea treatment products can be highly price sensitive (eg, pricing was a barrier in rural Madagascar). Thus partners must work to bring down prices in countries where they remain stubbornly high. Finally, support to the private sector needs to articulate a clear path towards the creation of a sustainable market. Subsidies for ORS may undermine sustainable markets, thus business models that encourage suppliers' reliance on external support risk being counter-productive in the long term. Few donor agencies recognize the importance of these domains of health services delivery to readily invest in them; public-private partnerships could lend support for this concept.

We found little information on the cost of scale-up efforts, primarily because this information has not historically been well-documented. We know that scale-up was done sustainably (and presumably affordably) in the five "successful" (>66\% coverage) countries studied, and we have some anecdotal evidence from interviews and reports from major funders, but this is a gap in knowledge within the global community. To address this gap in future work, donors and governments would be wise to develop a rigorous monitoring and evaluation plan to track the impact of their investments and begin to improve our understanding of cost and sustainability.

There are several important limitations of this study. These case studies were initially conceived to inform programmatic decisions for the Bill \& Melinda Gates Foundation; we recognize that the methods used did not emphasize repeatability as strongly as they would have done had our initial purpose been to publish these results in an academic journal. However, as important results came to light through this work, sharing the findings through academic means seemed appropriate. We therefore urge other researchers to look again at these and similar experiences with a view to obtaining further policy-relevant findings on factors leading to successful ORS scale-up.

As previously noted, ORS coverage rates in the 1980s were available for few countries, but have since improved with MICS and DHS [1]. Although we identified data sources for ORS coverage in 96 countries, these periodic surveys, one-time field studies, supply chain data and national surveys rely on caregiver recall of the illness episode and any treatment sought and provided. We selected a subset of all countries that have attempted to scale up ORS and for whom data were available at the time; it would be of interest to repeat the studies, drawing from a wider selection of country experiences, and to validate the findings of our quantitative analysis by ensuring that more than one assessor scores the various country factors.

Finally, we relied on impressions from key informants, who undoubtedly had extensive knowledge of the historical contexts, the actors involved and the issues. We cannot rule out the potential reporting bias inherent in the role that the key informants or their organizations played in promoting ORS use. We did not maintain tape recorded interviews, as we suspected that key informants would not be as open to sharing their perceptions if they were being recorded. Although we developed one interview guide, given the semistructured nature of the interviews interview questions were not completely standardized across countries.

\section{CONCLUSIONS}

This study was an in-depth effort to objectively gather and compare the limited data available on the factors associated with successful and unsuccessful scale-up of ORS programs. We identified a number of characteristics of successful ORS scale-up programs, including involvement of a broad range of key players, addressing supply and demand generation together, and working with both public and pri- 
vate sectors. Failure to involve key partners will often result in major gaps in the scale-up plan and critically affect sustainability. We found that the cost of scale-up efforts has not historically been well-documented. There are implications for the way that future ORS scale-up efforts should be directed to avoid some of the mistakes of the past. Efforts must synchronize demand generation, private provider outreach and public sector work. Rigorous monitor- ing and evaluation plans to track program impacts should be developed to address the gap in knowledge within the global community and improve our understanding of cost and sustainability. Future studies revealing lessons from other country experiences could also contribute to efforts to scale-up access to ORS and ultimately improve the lives of children who benefit the most from these efforts.

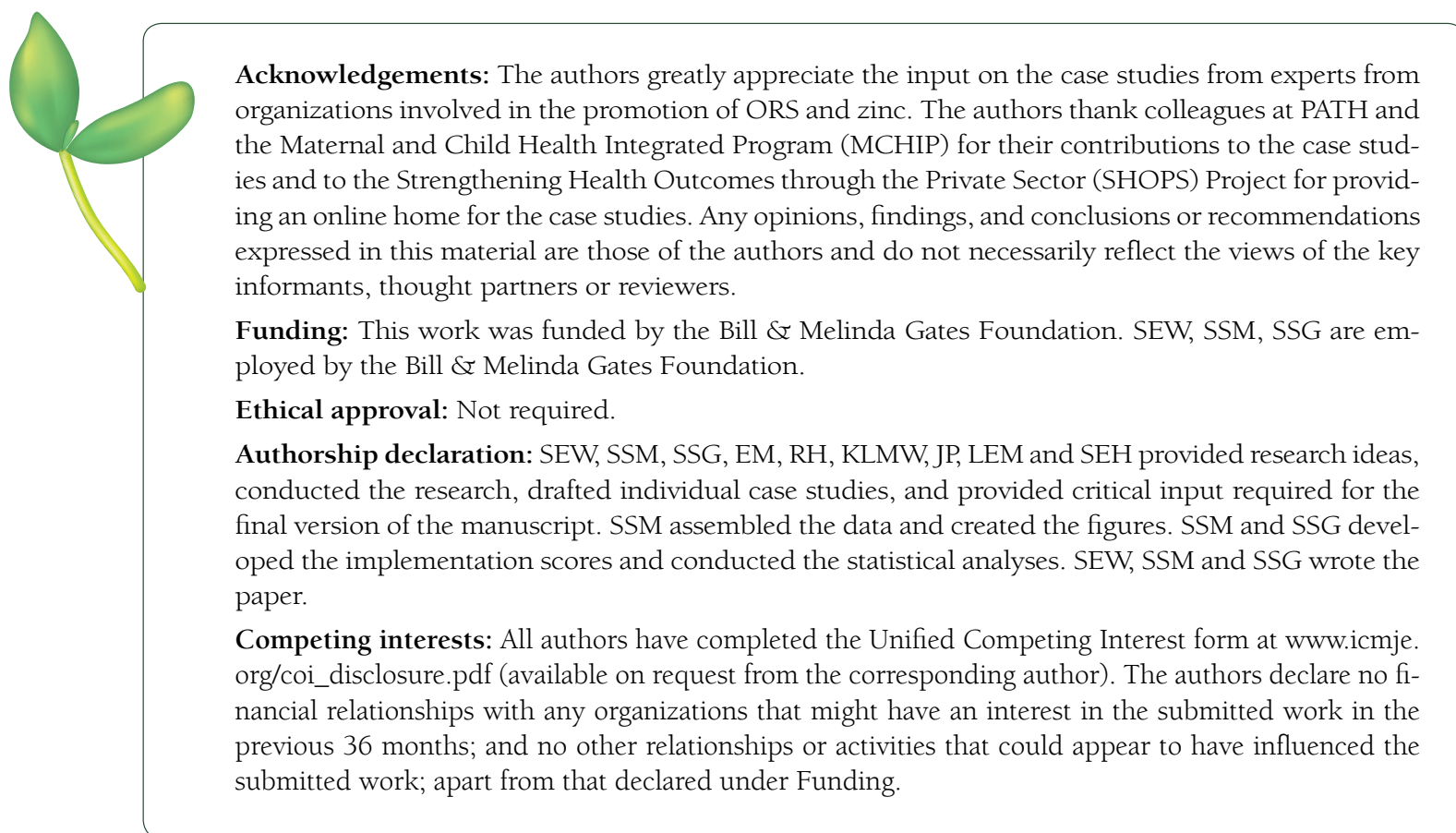

1 Victora CG, Bryce J, Fontaine O, Monasch R. Reducing deaths from diarrhoea through oral rehydration therapy. Bull World Health Organ. 2000;78:1246-55. Medline:11100619

2 UNICEF. Pneumonia and Diarrhoea: Tackling the deadliest diseases for the world's poorest children. New York: UNICEF, 2012. Available from: http://www.unicef.org/media/files/UNICEF_P_D_complete_0604.pdf. Accessed: 28 March 2013.

3 Claeson M, Waldman RJ. The evolution of child health programmes in developing countries: from targeting diseases to targeting people. Bull World Health Organ. 2000;78:1234-45. Medline:11100618

4 Lambrechts T, Bryce J, Orinda V. Integrated management of childhood illness: a summary of first experiences. Bull World Health Organ. 1999;77:582-94. Medline:10444882

5 Jones G, Steketee RW, Black RE, Bhutta ZA, Morris SS; Bellagio Child Survival Study Group. How many child deaths can we prevent this year? Lancet. 2003;362:65-71. Medline:12853204 doi:10.1016/S01406736(03)13811-1

6 UNICEF. Childinfo. Available from: www.childinfo.org. Accessed: 28 March 2013.

7 MEASURE DHS. Available from: www.measuredhs.com. Accessed: 28 March 2013.

8 UNICEF. Multiple Indicator Cluster Surveys. Available from: www.childinfo.org/mics.html. Accessed: 28 March 2013.

9 Kindler M. Preventing diarrheal deaths in Egypt. In millions saved: case studies in global health. Available from: http://www.cgdev.org/doc/millions/MS_case_8.pdf. Accessed: 28 March 2013.

10 Boschi-Pinto C, Lanata C, Black R. The global burden of childhood diarrhoea. In: Ehiri J, ed. Maternal and child health: Global challenges, programs, and policies. pp. 225-243. New York: Springer Verlag, 2009.

11 Mosites E, Hackleman R, Weum KLM, Pintye J, Manhart LE, Hawes SE. Bangladesh ORS case study. Seattle, 2012. Available from: http://www.shopsproject.org/resource-center/bangladesh-ors-case-study. Accessed: 28 March 2013.

12 Mosites E, Hackleman R, Weum KLM, Pintye J, Manhart LE, Hawes SE. Guyana ORS Case Study. Seattle, 2012. Available from: http://www.shopsproject.org/resource-center/guyana-ors-case-study. Accessed: 28 March 2013. 
13 Wilson SE, Morris SS, Gilbert SS. India ORS Case Study. Seattle; 2012. Available from: http://www.shopsproject.org/resource-center/india-ors-case-study. Accessed: 28 March 2013.

14 Gilbert SS, Morris SS, Wilson SE. Madagascar ORS Case Study. Available from: http://www.shopsproject.org/ resource-center/madagascar-ors-case-study. Accessed: 28 March 2013.

15 Morris SS, Gilbert SS, Wilson SE. Malawi ORS case study. Seattle, 2012. Available from: http://www.shopsproject.org/resource-center/malawi-ors-case-study. Accessed: 28 March 2013.

16 Wilson SE, Morris SS, Gilbert SS. Senegal ORS case study. Seattle; 2012. Available from: http://www.shopsproject.org/resource-center/senegal-ors-case-study. Accessed: 28 March 2013.

17 Wilson SE, Morris SS, Gilbert SS. Sierra Leone ORS case study. Seattle, 2012. Available from: http://www.shopsproject.org/resource-center/sierra-leone-ors-case-study. Accessed: 28 March 2013.

18 Wilson SE, Morris SS, Gilbert SS. Tanzania ORS case study. Seattle, 2012. Available from: http://www.shopsproject.org/resource-center/tanzania-ors-case-study. Accessed: 28 March 2013.

19 Mosites E, Hackleman R, Weum KLM, Pintye J, Manhart LE, Hawes SE. Trinidad \& Tobago ORS case study. Seattle, 2012. Available from: http://www.shopsproject.org/resource-center/trinidad-and-tobago-ors-case-study. Accessed: 28 March 2013.

20 Mosites E, Hackleman R, Weum KLM, Pintye J, Manhart LE, Hawes SE. Bangladesh Zinc case study. Seattle, 2012. Available from: http://www.shopsproject.org/resource-center/bangladesh-zinc-case-study. Accessed: 28 March 2013.

21 Gilbert SS, Morris SS, Wilson SE. Madagascar Zinc case study. Seattle, 2012. Available from: http://www.shopsproject.org/resource-center/madagascar-zinc-case-study. Accessed: 28 March 2013.

22 Mosites E, Hackleman R, Weum KLM, Pintye J, Manhart LE, Hawes SE. Nepal Zinc case study. Seattle, 2012. Available from: http://www.shopsproject.org/resource-center/nepal-zinc-case-study. Accessed: 28 March 2013.

23 Wilson SE, Morris SS, Gilbert SS. Tanzania Zinc case study. Seattle, 2012. Available from: http://www.shopsproject.org/resource-center/tanzania-zinc-case-study. Accessed: 28 March 2013.

24 UNICEF. Available from: http://www.unicef.org. Accessed: 28 March 2013.

25 World Health Organization. Available from: http://www.who.int. Accessed: 28 March 2013.

26 World Bank. Available from: http://www.worldbank.org. Accessed: 28 March 2013.

27 USAID Development experience clearinghouse. Available from: http://dec.usaid.gov. Accessed: 28 March 2013.

28 MEASURE DHS. Demographic and health surveys. Available from: http://www.measuredhs.com/What-WeDo/Survey-Types/DHS.cfm. Accessed: 28 March 2013.

29 UNICEF. Multiple indicator cluster surveys. Available from: http://www.childinfo.org/mics.html. Accessed: 28 March 2013.

30 MEASURE DHS. Malaria Indicator Surveys. Available from: http://www.measuredhs.com/What-We-Do/SurveyTypes/MIS.cfm. Accessed: 28 March 2013.

31 MEASURE DHS. Service provision assessment surveys. Available from: http://www.measuredhs.com/WhatWe-Do/Survey-Types/SPA.cfm. Accessed: 28 March 2013.

32 World Health Organization/Health Action International. Available from: http://www.haiweb.org/medicineprices. Accessed: 28 March 2013.

33 Cuzick J. A Wilcoxon-type test for trend. Stat Med. 1985;4:87-90. Medline:3992076 doi:10.1002/ $\operatorname{sim} .4780040112$

34 International Rescue Committee (IRC) \& United States Agency for International Development. (USAID). IRC Sierra Leone Child Survival Grant in Kono District, CSHGP Cycle XIX, 2003 - 2008: Mid-Term Evaluation Report. Freetown, New York and Kono: USAID; 2006.

35 Government of Sierra Leone. Free healthcare services for pregnant and lactating women and young children in Sierra Leone, 2009. Available from: http://unipsil.unmissions.org/portals/unipsil/media/publications/free_ services_framewk_nov09.pdf. Accessed: 28 March 2013.

36 Amnesty International. Sierra Leone: At a crossroads: Sierra Leone's free health care policy. London: Amnesty International, 2011. Available from: https://doc.es.amnesty.org/cgi-bin/ai/BRSCGI/AT\%20A\%20CROSSROADS\%2OSIERRA\%2OLEONE\%E2\% 80\%99S\%20FREE\%20HEALTH\%2OCARE\%2OPOLICY?CMDVEROBJ\&MLKOB=29944170909. Accessed: 28 March 2013.

37 Maxmen A. Sierra Leone's free health-care initiative: work in progress. Lancet. 2013;381:191-2. Medline:23346591 doi:10.1016/S0140-6736(13)60074-4

38 Briggs J, Gabra M, Ickx P. Senegal Assessment: Drug Management for Childhood Illness. Published for the U.S. Agency for International Development by Rational Pharmaceutical Management Plus. Arlington, VA: Management Sciences for Health, 2002. Available from: http://www.google.com/url?sa=t\&rct=j\&q=senegal $\% 20$ assessment\%3A\%20drug\%20management\%20for\%20childhood\%20illness.\%20\&source=web\&cd=1\&ved= OCDQQFjAA\&url=http\%3A\%2F\%2Fwww. afro.who.int\%2Findex.php\%3Foption \% 3Dcom_ docman\%26task\%3Ddoc_download\%26gid\%3D655\&ei=3ftVUfHUGomWiAK57YDYCA\&usg=AFQjCNFU dhoUpw5MkkU58g4mL90_yITtCg. Accessed: 28 March 2013.

39 United States Agency for International Development (USAID) \& Maternal and Child Health Integrated Program. (MCHIP). Integrated community case management of childhood illness: Documentation of best practices and bottlenecks to program implementation in Senegal. New York: USAID, 2012. 
40 Agence Nationale de la Statistique et de la Démographie (ANSD) [Sénégal], et ICF International. Enquęte Démographique et de Santé ŕ Indicateurs Multiples au Sénégal (EDS-MICS) 2010-2011. Calverton: ANSD et ICF International, 2012. Available from: http://www.ansd.sn/publications/rapports_enquetes_etudes/enquetes/ EDS-MICS_2010-11_Rapport-final.pdf. Accessed: 28 March 2013.

41 Pan American Health Organization. Cholera Situation in the Americas. Epidemiological Bulletin. 1996;18(1). Available from: http://wwwl.paho.org/english/sha/epibul_95-98/be971cho.htm. Accessed: 28 March 2013.

42 Adams W, Bratt DE. Young coconut water for home rehydration in children with mild gastroenteritis. Trop Geogr Med. 1992;44:149-53. Medline:1496708

43 World Health Organization (WHO). Country Profile: Trinidad and Tobago, 2012. Available from: http://www. who.int/gho/countries/tto.pdf. Accessed: 28 March 2013.

44 Gilroy KE, Callaghan-Koru JA, Cardemil CV, Nsona H, Amouzou A, Mtimuni A, et al; CCM-Malawi Quality of Care Working Group. Quality of sick child care delivered by Health Surveillance Assistants in Malawi. Health Policy Plan. 2012 Oct 13. [Epub ahead of print]. Medline:23065598 doi:10.1093/heapol/czs095

45 Danart A, Machie W, Cisek C, Kondoole N, Chizani N. Midterm Evaluation of Population Services International's Improving Health Through Social Marketing Project. Washington DC: The Population Technical Assistance Project, 2004.

46 Bureau of Statistics Planning Commission Tanzania and Macro International Inc. Tanzania demographic and health survey 1991/1992. Dar es Salaam and Columbia; 1993. Available from: http://www.measuredhs.com/ pubs/pdf/FR45/FR45.pdf. Accessed: 28 March 2013.

47 Armstrong Schellenberg JR, Adam T, Mshinda H, Masanja H, Kabadi G, Mukasa O, et al. Effectiveness and cost of facility-based Integrated Management of Childhood Illness (IMCI) in Tanzania. Lancet. 2004;364:158394. Medline:15519628 doi:10.1016/S0140-6736(04)17311-X

48 National Bureau of Statistics [Tanzania] and Macro International Inc. Tanzania Service Provision Assessment Survey 2006. Dar es Salaam: National Bureau of Statistics and Macro International Inc. Available from: http:// www.measuredhs.com/publications/publication-SPA12-SPA-Final-Reports.cfm. Accessed 28 March 2013.

49 World Health Organization /Health Action International. International Medicine Price Workbook - Part I, released 4 September 2009. Geneva: WHO, 2009.

50 Management Sciences for Health. East Africa Drug Sellers Initiative: Tanzania Results Summary. Dar es Salaam; 2011. Available from: http://www.drugsellerinitiatives.org/DSI-PDF-Documents/upload/eadsi_tanzania_results_summary.pdf. Accessed: 28 March 2013.

51 POUZN Project. Introducing improved treatment of diarrhea with zinc and ORT in Tanzania: A public-private partnership supported by the POUZN/AED Project. Washington DC: Point-of-use water disinfection and zinc treatment (POUZN) Project, AED, 2010. Available from: http://www.zinctaskforce.org/wp-content/uploads/2012/11/1_Cross-cutting-Introducing-Improved-Treatment-of-Childhood-Diarrhea-Final.pdf. Accessed 28 March 2013.

52 Macdonald V, Banke K. Assuring access to pediatric zinc for diarrhea treatment through the private sector in Madagascar: Results and lessons learned. Social marketing Plus for Diarrheal Disease Control: Point-of-use Water Disinfection and Zinc treatment (POUZN) Project. Bethesda: Abt Associates Inc. and Population Services International, 2010. Available from: http://www.shopsproject.org/sites/default/files/resources/Madagascar_FINAL\%20for\%20web.pdf. Accessed: 28 March 2013.

53 Chowdhury M, Cash R. A simple solution: Teaching millions to treat diarrhoea at home. Dhaka: University Press Limited, 1996.

54 Social Marketing Co. Sales Network. Available from: http://www.smc-bd.org/sales.html. Accessed: 28 March 2013.

55 National Institute of Population Research and Training (NIPORT), Mitra and Associates, and ICF International. Bangladesh Demographic and Health Survey 2011. Dhaka, Bangladesh and Calverton, Maryland, USA: NIPORT, Mitra and Associates, and ICF International, 2013. Available from: http://www.measuredhs.com/pubs/ pdf/FR265/FR265.pdf. Accessed: 28 March 2013.

56 Viswanathan H, Rohde J. Diarrhoea in Rural India: A Nationwide Study of Mothers and Practitioners. All India Summary. New Delhi: Vision Books, 1990.

57 Private Sector Partnership - One (PSP-One). Saathi Bachpan Ke- Promoting Diarrhea Management Through the Private Sector in Urban North India. 2008. Available from: http://www.shopsproject.org/sites/default/files/ resources/4769_file_Sathi_Bachpan_Ke.pdf. Accessed: 28 March 2013.

58 World Health Organization. The world health report: health systems financing: the path to universal coverage. Geneva: World Health Organization, 2010. Available from: http://www.who.int/entity/whr/2010/whr10_ en.pdf. Accessed: 28 March 2013. 